\title{
Quantitative High-resolution Computed tomography Analysis of Antisynthetase Syndrome with Interstitial Pneumonia
}

\section{Xueren Li}

Haihe clinical college of Tianjin medical universtity https://orcid.org/0000-0001-9610-0644

\section{Shouchun Peng}

Haihe Clinical college of Tianjin medical University

Qi Wu ( $D$ haiheyywuqi@163.com )

Haihe Clinical College of Tianjin Medical University

\section{Huarui Zhang}

Haihe clinical college of Tianjin medical University

\section{$\mathrm{Na}$ Feng}

Dongli Hospital ,Tianjin

\section{Yuhua Zhang}

Pingjin Hospital ,Tianjin

\section{Research}

Keywords: Antisynthetase syndrome, High-resolution computed tomography,Quantitative analysis,Nonspecific interstitial pneumonia, Organizing pneumonia

Posted Date: March 3rd, 2021

DOl: https://doi.org/10.21203/rs.3.rs-259229/v1

License: (c) (i) This work is licensed under a Creative Commons Attribution 4.0 International License. Read Full License 


\section{Abstract}

Background Non-specific interstitial pneumonia (NSIP) combined with organizing pneumonia (OP) pattern has been confirmed in pathology or radiology. This study is to analyze the correlation between high-resolution computed tomography (HRCT) quantitative indexes (QI) and pulmonary function test parameters (PFTs), and compare differences of HRCT patterns in Antisynthetase Syndrome with interstitial pneumonia (ASS-IP).

Methods Data of ASS-IP patients admitted to respiratory department of Ping Jin hospital from January 2014 to December 2019 were retrospectively reviewed.

Results 21 ASS-IP patients were enrolled in this study and 3 patients were NSIP, 9 patients were OP and 8 patients were NSIP overlap OP (NSIP/OP) pattern. (1) Volume, Weight percentages of the extracted whole lung volume with attenuation values $(\mathrm{V} \%, \mathrm{~W} \%)$ and mean lung attenuation (MLA) of non-aerated area is $5.69 \%, 16.43 \%$ and -11.76 Hounsfield unit $(\mathrm{Hu})$. Total MLA of attenuation values $\left(\mathrm{MLA}_{\text {total }}\right)$ is $-678.97 \mathrm{Hu}$. (2) $F V C$ and MLA of poorly aerated $\triangle r=0.58, P=0.048 \rrbracket, F E V_{1}$ and $M L A \otimes r=0.79, P=0.001 \rrbracket$ of poorly aerated, $\mathrm{FEV}_{1} / \mathrm{FVC} \otimes r=0.23, \mathrm{P}=0.01 \rrbracket$ and MLA of normally lung aerated, have linear correlation .(3) DLCO ( $\left.\mathrm{P}=0.049\right)$, volume of poorly aerated $\left(\mathrm{V}_{\text {fibrosis }} \%, \mathrm{P}=0.03\right)$, and weight of hyper inflated $\left(\mathrm{W}_{\text {hyper }} \%, \mathrm{P}=0.02\right)$ percentages, and $\mathrm{MLA}_{\text {total }}(\mathrm{P}=0.01)$ have significant statistic differences between patients with NSIP/OP or OP patterns, but the therapy improvement time $(P=0.41)$ had no difference.

Conclusions QI of HRCT has a good correlation with PFTs and partly reference value to pathological classification of ASS-IP. NSIP/OP may be a common pattern in ASS-IP, fibrosis severity of which is more severe than OP.

\section{Background}

Antisynthetase syndrome (ASS) is a subtype of Dermatomyositis and Polymyositis (DM/PM), which has characteristic changes, that together with interstitial pneumonia (IP), inflammatory arthritis, fever, Raynaud phenomenon and mechanic's hands [1].Serum anti-Jo-1 is the most frequent positive antibody in a patient. However, other specific anti-Antisynthetase冈such as anti-alanyl (PL-12), anti-threonyl (PL-7), and anti-glycyl (EJ) tRNA-synthetase antibodies have been found routinely[2].In addition, some previous autoimmune antibodies have also been reported to associate with the development of ASS with interstitial pneumonia (ASS-IP), such as anti RO-52[3].

Non-specific interstitial pneumonia (NSIP) or organizing pneumonia (OP) is pathology or radiology patterns, pathogenic factors of which included idiopathic or secondary forms. High-resolution computed tomography (HRCT) pattern of connective tissue diseases (CTDs) associated with IP can be classified by the criterion of idiopathic IP guidelines [4]. Pathological studies of lung fibrosis detected some biopsies shown NSIP overlap OP (NSIP/OP) along bronchial blood vessel bundle with bilateral the lower lobes 
subpleural region predominance [5-7] $(4,5,6)$.It reported that NSIP or NSIP/OP pattern is accounted for $74-90 \%[8,9]$ in DM/PM.

HRCT can provide classification of IP patterns and assessment of IP severity and therapeutic guide. Computer-aided quantitative analysis (QA) is substituted visual appraisal due to its accuracy and objectivity, of which the threshold mask method is more popular because of its availability [10]. In this article, we analyzed clinical character of ASS-IP patients and were looking for HRCT quantitative associations with clinical pulmonary functions test parameters (PFTs).

\section{Patients And Method}

\section{Patient}

We performed a retrospective review data of antisynthetase antibodie positive patients admitted to respiratory department of Ping Jin hospital from January 2014 to December 2019. Patient diagnosed as ASS-IP met IP guideline [11] and the criterion proposed by Connors colleagues [12, 13].Collected and recorded the basic information of patients recruited, laboratory test results, treatment strategies and follow-up data respectively.

\section{HRCT scan and QA}

HRCT imaging was performed with a 64 section mufti-detector CT scanner (GE Healthcare, Milwaukee, WI). The QA of HRCT was obtained using a commercially available workstation by two chest radiologists (Zhao da Wei and Yin liang) with 10 years' experience. The standard based by characters of signs and distribution of HRCT and criteria recommended in previous literature $[14,15]$. In each slice, the operator manually outlined the lung borders through selecting the total lung tissue and excluding the heart, the central airways, and the major blood vessels. Total lung volume (TLV) was described as lung parenchymal volume of outlined lung area .TLV and mean lung attenuation (MLA) can be calculated by Workstation. Attenuation area ranges were defined differently aerated lung compartments: non aerated,100 to +100 Hounsfield unit $(\mathrm{Hu})$, which represent the areas of pulmonary consolidation [16]; poorly aerated and fibrosis (fibrosis), -101 to $-500 \mathrm{Hu}$, which represent the areas of ground-glass opacity and reticulation; normally lung aerated(normal), -501 to-900 Hu; and hyper inflated (hyper), -901 to-1,000 Hu $[17,18]$.Volumes\% and weight $\%$ of Attenuation area were calculated as percentages of the extracted whole lung volume with attenuation values ranging from $100 \mathrm{Hu}$ to $-1000 \mathrm{Hu}[17,18] . \mathrm{A} \mu$ value is assigned to each voxel ( $\mu$ voxel), roughly proportional to its density, and is expressed as a CT number standardized to that of water. CT value $=1000 \times \mu$ voxel $-\mu$ water $/ \mu$ water [16].Proportional weight $=\mu$ voxel $\times$ proportional Volumes.

\section{PFTs}


PFTs performed by a spirometer (JAEGER Master Screen) are used for diagnosis and monitoring of ASSIP patients, including FVC, FEV1, FEV1/ FVC, carbon monoxide diffusion (DLCO).

\section{Treatment strategies and the evaluation of effect}

Glucocorticoids and immunosuppressant strategies of each patient were studied and therapeutic effect was evaluated by changes of FVC or DLCO [19].Moreover, if one patient had no HRCT in the follow up, we defined patient as improvement case by 10 percent of $V_{\text {normal }} \%$ over the baseline value and recorded the length of the treatment.

\section{Statistical analysis}

Patients' data were analyzed by Spss 19.0 statistical software. Their data were described as mean, interquartile range or as percentage of the relative frequency according to the different. Categorical data were compared with using the $\chi 2$ test or Fisher's exact probability test for independence. Correlation analysis between PETs and different differently aerated lung compartments quantitative parameters. $\mathrm{P}<$ 0.05 was considered as statistically significant.

\section{Results}

This study included a total of 21 ASS-IP patients and baseline clinical characteristics show Table 1.The median age at diagnosis was 51 years, 13 patients were female and 8 were smokers. Serum antibody test showed 4 patients were positive anti-PL-7, 7 patients were positive anti-Jo-1, 6 patients were anti- PL-12 and 3 patients were anti-EJ. There are 15 patients with cough, 11 patients with dyspnea, and 21 patients with crackles in the lower pulmonary lobes. Beside serum positive Anti-synthase antibody, autoimmune serology test was positive for ANA, rheumatoid factor IgM and antibodies to Ro-52.Arterial blood gas (ABS) indicated hypoxemia in most cases. Respiratory symptoms or CTDs related symptoms and physical findings, PFTs and ABS were not different between two groups. 
Table 1

Comparison of clinical characteristics of ASS patients

\begin{tabular}{|c|c|}
\hline & Total \\
\hline Number of patients, $n$ & 21 \\
\hline $\operatorname{Sex}(M: F)$ & $8: 13$ \\
\hline Age, median years, $95 \% \mathrm{Cl}$ & $51.00(45.25-56.75)$ \\
\hline Smoking habit,n(\%) & $8(38.10 \%)$ \\
\hline Disease duration, $95 \% \mathrm{Cl}$ & $4.14(1.36-6.92)$ \\
\hline \multicolumn{2}{|l|}{ Symptoms } \\
\hline Dyspnea,n(\%) & $11(52.38 \%)$ \\
\hline Cough,n(\%) & $15(71.43 \%)$ \\
\hline Fever,n(\%) & $3(14.29 \%)$ \\
\hline \multicolumn{2}{|l|}{ Physical fidings } \\
\hline Raynaud's phenomenon,n(\%) & $2(9.52 \%)$ \\
\hline Skin lesion, $\mathrm{n}(\%)$ & $6(28.57 \%)$ \\
\hline Fine crackle,n(\%) & $21(100 \%)$ \\
\hline Muscle weakness,n(\%) & $6(28.57 \%)$ \\
\hline Polyarthritis,n(\%) & $2(9.52 \%)$ \\
\hline Gottron's papules,n(\%) & $1(4.76 \%)$ \\
\hline Mechanic's hand,n(\%) & $12(57.14 \%)$ \\
\hline \multicolumn{2}{|l|}{ Laboratory test } \\
\hline $\mathrm{PaCO}_{2}, 95 \% \mathrm{Cl} \mathrm{mmHg}$ & $36.96(35.79-38.4)$ \\
\hline $\mathrm{FiO}_{2} 21 \%, \mathrm{PaO}_{2} \varangle 95 \% \mathrm{Cl} \mathrm{mmHg}$ & $74.33(68.18-80.48)$ \\
\hline FVC $\%, 95 \% \mathrm{Cl}$ & $57.98(50.87-6508)$ \\
\hline FEV1 \% $95 \% \mathrm{Cl}$ & $61.43(53.74-69.11)$ \\
\hline FEV1/FVC,95\% Cl & $79.74(73.05-86.44)$ \\
\hline DLCO $\%, 95 \% \mathrm{Cl}$ & $40.83(32.80-48.86)$ \\
\hline HRCT patterns & \\
\hline
\end{tabular}

n,number. NSIP,Non-specific interstitial pneumonia. OP, Organizing pneumonia 


\begin{tabular}{|lc|}
\hline & \multicolumn{1}{|c|}{ Total } \\
\hline NSIP,n(\%) & $3(14.29 \%)$ \\
\hline NSIP overlap OP,n(\%) & $8(38.10 \%)$ \\
\hline OP,n(\%) & $9(42.86 \%)$ \\
\hline n,number. NSIP,Non-specific interstitial pneumonia. OP, Organizing pneumonia \\
\hline
\end{tabular}

PFTs show a medium restrictive ventilation abnormalities and mild carbon monoxide diffusion barriers. HRCT revealed a NSIP, OP or NSIP/OP pattern was observed in 3 out of 21 (14.29\%), 9 out of 21 (42.86\%) and 8 out of 21 (38.08\%) patients. Meanwhile, NSIP pattern is 3 patients, NSIP/OP is 3 patients and OP is 1 patient in anti-JO-1(+) group and in anti-JO-1(-) group is 1, 8 and 5 patients respectively. One patient is NSIP, 3 patients were NSIP/OP and 5 patients were OP in histopathological patterns. Among pulmonary function parameters and aerated lung compartments quantitative values, $F V C$ and $\operatorname{MLA}_{\text {fibrosis }}(r=0.58, P=$ $0.048), F E V 1 / F V C$ and $M L A_{\text {normal }}(r=0.23, P=0.01)$, and FEV1\% and $M_{L} A_{\text {fibrosis }}(r=0.79, P=0.001)$ have good linear correlation (Fig. 1).

\section{Comparison of NSIP overlaps OP and OP patterns patients}

17 patients excluding NISP were classified into the group investigated with 8 patients with NSIP/OP and a control group with 9 OP patients (Table 2). HRCT patterns and associated 3D model of one female patient with serum anti-PL-12(+) show on Fig. 2. It found that DLCO, $\mathrm{V}_{\text {fibrosis }} \%, \mathrm{~V}_{\text {hyper }} \%, \mathrm{~W}_{\text {hyper }} \%$ and $M_{\text {Lotal }}$ (Figure3)have significant statistical differences between two groups (Fig. 3). Clinical symptoms and physical findings, PFTs and ABS have no significant difference. 
Table 2

Comparison of clinical parameters between patients with NSIP/OP and OP pattern

\begin{tabular}{|llll|}
\hline & NSIP/OP patient & OP patient & $\begin{array}{c}\text { P- } \\
\text { value }\end{array}$ \\
\hline Number of patients & 8 & 9 & \\
\hline $\mathrm{PaCO}_{2}, 95 \% \mathrm{Cl}, \mathrm{mmHg}$ & $35.80(34.52-37.08)$ & $38.02(36.06-39.98)$ & 0.049 \\
\hline $\mathrm{FiO}_{2} 21 \%, \mathrm{PaO}{ }_{2}, 95 \% \mathrm{Cl}, \mathrm{mmHg}$ & $77.99(66.40-89.58)$ & $75.56(64.59-86.52)$ & 0.73 \\
\hline $\mathrm{FVC} \%, 95 \% \mathrm{Cl}$ & $56.20(44.84-67.56)$ & $60.74(46.59-74.90)$ & 0.58 \\
\hline $\mathrm{FEV} 1 \%, 95 \% \mathrm{Cl}$ & $61.68(50.06-$ & $60.25(44.66-75.84)$ & 0.87 \\
\hline $\mathrm{FEV} 1 / \mathrm{FVC}, 95 \% \mathrm{Cl}$ & $73.23)$ & & 0.85 \\
\hline $\mathrm{DLCO} \%, 95 \% \mathrm{Cl}$ & $80.66(65.79-95.53)$ & $81.98(74.79-89.17)$ & 0.01 \\
\hline $\mathrm{V}_{\text {nonaerated } \%} \%$ & $29.60(16.80-42.41)$ & $48.95(39.73-58.17)$ & 0.07 \\
\hline $\mathrm{V}_{\text {fibrosis }} \%$ & $8.01(2.88-13.15)$ & $3.82(2.57-5.08)$ & 0.03 \\
\hline $\mathrm{V}_{\text {normal }} \%$ & $19.08(12.76-25.40)$ & $11.21(6.92-15.52)$ & 0.63 \\
\hline $\mathrm{V}_{\text {hyper }} \%$ & $62.10(53.56-$ & $59.57(51.42-67.72)$ & 0.63 \\
\hline $\mathrm{W}_{\text {nonaerated }} \%$ & $70.64)$ & & 0.03 \\
\hline $\mathrm{W}_{\text {fibrosis }} \%$ & $10.68(2.02-19.35)$ & $25.39(14.13-36.63)$ & 0.03 \\
\hline $\mathrm{W}_{\text {normal }} \%$ & $19.62(10.21-29.04)$ & $14.42(10.04-18.80)$ & 0.24 \\
\hline $\mathrm{W}_{\text {hyper }} \%$ & $34.25(26.73-41.77)$ & $27.14(22.06-32.23)$ & 0.08 \\
\hline $\mathrm{MLA}_{\text {nonaerated }}, \mathrm{Hu}$ & $44.00(33.24-54.75)$ & $52.17(46.15-58.19)$ & 0.13 \\
\hline $\mathrm{MLA}_{\text {fibrosis }}, \mathrm{Hu}$ & $2.11(0.29-3.94)$ & $6.27(3.22-9.32)$ & 0.02 \\
\hline & $-15.28(-25.92-$ & $-6.97(-11.71--2.23)$ & 0.10 \\
\hline
\end{tabular}

n,number. NSIP,Non-specific interstitial pneumonia. OP, Organizing pneumonia. $V_{\text {nonaerated }} \%$, $\mathrm{V}_{\text {fibrosis }} \%, \mathrm{~V}_{\text {normal }} \%$ and $\mathrm{V}_{\text {hyper }} \%$,Volume percentages of the extracted whole lung volume with attenuation values of non-aerated area, poorly aerated and fibrosis, normally lung aerated(normal) and hyper inflated. $\mathrm{W}_{\text {nonaerated }} \%, \mathrm{~W}_{\text {fibrosis }} \%, \mathrm{~W}_{\text {normal }} \%$ and $\mathrm{W}_{\text {hyper }} \%$,Weight percentages of the extracted whole lung volume with attenuation values of non-aerated area, poorly aerated and fibrosis ,normally lung aerated(normal) and hyper inflated.MLA, mean lung attenuation. MLA nonaerated, $M L A_{\text {fibrosis, }}, M L A$ normal, $M L A_{\text {hyper }}$ and $M L A_{\text {tota }}, M L A$ of the extracted whole lung volume with attenuation values of nonaerated area, poorly aerated and fibrosis ,normally lung aerated, hyper inflated area and outlined total lung area. ET, Effective time of treatment. 


\begin{tabular}{|c|c|c|c|}
\hline & NSIP/OP patient & OP patient & $\begin{array}{l}\mathrm{P} \text { - } \\
\text { value }\end{array}$ \\
\hline $\mathrm{MLA}_{\text {normal}}, \mathrm{Hu}$ & $\begin{array}{l}-747.91(-767.65- \\
-728.18)\end{array}$ & $\begin{array}{l}-772.83(-796.33- \\
-749.33)\end{array}$ & 0.08 \\
\hline $\mathrm{MLA}_{\text {hyper }}, \mathrm{Hu}$ & $\begin{array}{l}-934.23(-944.06- \\
-924.40)\end{array}$ & $\begin{array}{l}-941.31(-947.03- \\
-935.60)\end{array}$ & 0.15 \\
\hline $\mathrm{MLA}_{\text {total }}, \mathrm{Hu}$ & $\begin{array}{l}-628.03(-701.51- \\
-554.54)\end{array}$ & $\begin{array}{l}-735.61(-790.96- \\
-680.27)\end{array}$ & 0.01 \\
\hline \multicolumn{4}{|l|}{ Treatment } \\
\hline $\begin{array}{l}\text { Glucocorticoids combined with } \\
\text { immunosuppressants,n }\end{array}$ & 8 & 9 & \\
\hline Tacrolimus,n(\%) & $4(50.00 \%)$ & $3(33.33 \%)$ & 0.64 \\
\hline Azathioprine,n(\%) & $1(12.5 \%)$ & $1(11.11 \%)$ & 1 \\
\hline Cyclophosphamides + Tacrolimus,n(\%) & $2(25.00 \%)$ & $0(0)$ & 0.21 \\
\hline Cyclosporin a,n(\%) & $0(0)$ & $4(44.44 \%)$ & 0.08 \\
\hline Cyclophosphamide,n(\%) & $1(12.5 \%)$ & $0(0)$ & 0.47 \\
\hline Mycophenolate mofetil,n(\%) & $0(0)$ & $1(11.11 \%)$ & 1 \\
\hline Death,n(\%) & $1(12.5 \%)$ & $0(0)$ & 0.47 \\
\hline ET & $3.44(1.90-5.90)$ & $2.86(1.40-4.31)$ & 0.41 \\
\hline \multicolumn{4}{|c|}{ 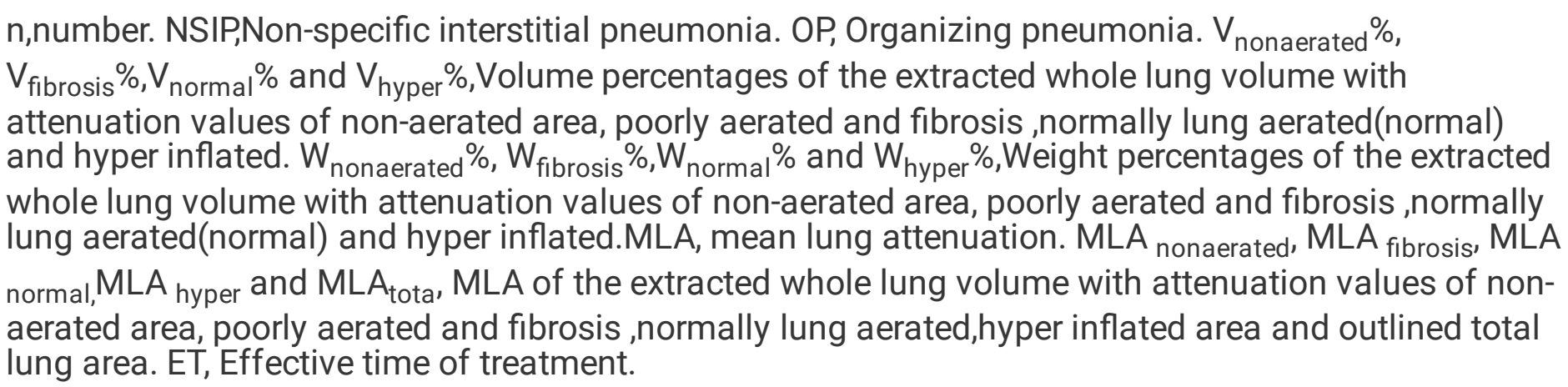 } \\
\hline
\end{tabular}

\section{Treatment strategies and follow-up}

All patients were given to treatment strategies with glucocorticoids combined with immunosuppressants. During follow-up, 3 patients lost connections ( 1 patient died of respiratory failure after 20 months of treatment,2 patients were out of touch).The improvement time is taken from 1 to 6 months and it found that there is no different between NSIP/OP and OP patterns groups.

\section{Discussion}


IP is one of the most common CTDs with high morbidity and mortality [20], while the ASS-IP is a special type of IP. The diagnosis of ASS-IP requires not only evidence of ILD, such as pathology and HRCT images, but also evidence of positive serum antibodies, just mentioned in methods. Hence that ASS-IP is also a rare type in clinic. In this study, we had retrospectively collected 23 cases of ASS-IP which were diagnosed and treated in our hospital in the past 5 years. All cases meet the diagnosis and exclusion criteria. Among the 23 patients, the mean age is 51 years old and female accounts for the most. Dyspnea and cough are common symptoms. Fine crackle can be heard in all patients. Mechanic's hand is major sign of rheumatic diseases. Previous research suggested that pulmonary arterial hypertension has a low prevalence in ASS-IP compared with other CTDs, but it independently affects prognosis and survival [21]. In our study, one out of the 23 patients had pulmonary arterial hypertension and died after 20 months follow-up in this study. Tacrolimus is main immunosuppressants used as the standardized treatment and the patients can improve after the standardized treatment for mean 3.44 months.

Interpretations from radiologists on HRCT were mainly based on visual assessment. Some investigators used semiquantitative way to evaluate severity and monitor progression of disease, and score the IP by the international Goh score with evaluation at 5 lung levels [22, 23]. However, its result cannot represent the whole lung actuality because of limited levels analysis. QA of HRCT has been widely carried out in both researches and clinical practice in recent years. Through analyzing HRCT image, a serial of parameters could be acquired, such as average density, texture analysis and threshold segmentation in high attenuation areas

Threshold segmentation software is popularly used by the operator at home and abroad because of easy availability. It can quantify interstitial lung changes by setting different threshold value range. Under functioning lung volume $(-700 \mathrm{Hu}>$ pixel $>-950 \mathrm{Hu})$ and IP volume $(>-700 \mathrm{Hu})$,quantitative indexes showed good correlation not only with the extent of IP estimated by visual inspection but also with PFT results[24].Another study found that when the high attenuation area (threshold value $>-500 \mathrm{Hu}$ ) was defined as follows IP, and percent of which were significantly correlated with DLCO [25].Considering the performance of the consolidation pattern of ASS-IP patient, the high attenuation area between - 100 to $100 \mathrm{Hu}$ is also analyzed and defined as non-aerated areas in our research. Among pulmonary function parameters and aerated lung compartments quantitative values, $F V C \%$ and $\operatorname{MLA}_{\text {fibrosis }}(r=0.58, P=$ $0.048), F E V 1 / F V C$ and $M L A_{\text {normal }}(r=0.23, P=0.01)$, and FEV1\% and $M_{\text {L }} A_{\text {fibrosis }}(r=0.79, P=0.001)$ have good linear correlation .CTD associated IP often present either an NSIP or OP pattern. NSIP/OP pattern has been confirmed by some clinicopathological studies[26],which was reported to be associated with CTDs[5].Therefore, we focused on comparing quantitative indexes between NSIP/OP and OP pattern in DM/PM-IP patient and it found that DLCO. $\mathrm{V}_{\text {fibrosis }} \%, \mathrm{~V}_{\text {hyper }} \%, \mathrm{~W}_{\text {hyper }} \%$ and $\mathrm{MLA}_{\text {total }}$ have significant statistical differences. On one hand, lower DLCO and higher $\mathrm{V}_{\text {fibrosis }} \%$ indicated that severity of fibrosis of NSIP/OP is worse than OP group. On the other hand, $\mathrm{V}_{\text {hyper }} \%$ and $\mathrm{W}_{\text {hyper }} \%$ are higher in the OP group demonstrate that -901 to $-1000 \mathrm{Hu}$ area relatively increased under the influence of non-aerated areas with consolidation pattern. Moreover, $\mathrm{MLA}_{\text {total }}$ is an overall assessment of $100 \mathrm{in}-1000 \mathrm{Hu}$. 
Our study has some limitations. On one hand, it was a retrospective and single-center study of a small number of patients. One other hand, the diagnosis of NSIP, OP or NSIP/OP pattern based on histopathological diagnosis was carried out only in 8 patients.

\section{Conclusion}

QI of HRCT has good correlation with PFT parameters in ASS patient. NSIP/OP is a common pattern in ASS-IP, fibrosis severity of which is more severe than OP. Furthermore, QA can open a new sight on HRCT, as it is capable of provides accurate IP interpretation, especially the condition with lack pulmonary pathological evidence. And the high attenuation area between -100 to100 Hu should be paid attention to additional analysis except general threshold value range in these groups.

\section{Abbreviations}

NSIP :Non-specific interstitial pneumonia (NSIP) combined with organizing ;OP:pneumonia ; HRCT: highresolution computed tomography ; QI: quantitative indexes ; ASS-IP : Antisynthetase Syndrome with interstitial pneumonia; NSIP overlap OP: NSIP/OP; MLA: mean lung attenuation ; PFTs: pulmonary function test parameters; FVC: forced vital capacity ; DLCO: carbon monoxide diffusing capacity; DM/PM : Dermatomyositis and Polymyositis; CTDs : connective tissue diseases; QA: quantitative analysis ; TLV : Total lung volume; ABS : Arterial blood gas; Hu : Hounsfield unit.

\section{Declarations}

\section{Acknowledgements}

We thank two radiologists, Zhaoda Wei and Yin liang, Department of respiratory and critical care medicine, Affiliated Hospital of Logistics University of Chinese people's Armed Police Force. We wish to express our sincere gratitude to Professor Hongzhi Yu, Department of Basic Medicine, Haihe Clinical College of Tianjin Medical University, for his valuable advice on statistics.

\section{Funding}

No funding.

\section{Availability of data and materials}

The datasets, as well as the patent materials, used and analyzed during the current study are available from the corresponding author on reasonable request.

\section{Authors' contributions}


Xueren $\mathrm{Li}$ is the guarantor of this research. Na Feng contributed to patient recruitment and patient followup. Shouchun Peng,Qi Wu were responsible for outcome measurement.Yuhua Zhang finished data acquisition. Huarui Zhang finished data analysis. All authors contributed to the drafting of this manuscript. All authors read and approved the final manuscript.

\section{Ethics approval and consent to participate}

Prior to its start, the study approved by the ethics committee of Pingjin Hospital,

Tianjin, China. The reference number for the study is 2019-0007.

\section{Consent for publication}

Not applicable.

\section{Competing interests}

No conflict of interest was declared by the authors.

\section{References}

1. Katzap E, Barilla-LaBarca ML, Marder G: Antisynthetase syndrome. Curr Rheumatol Rep 2011, 13:175-181. doi:10.1007/s11926-011-0176-8.

2. Fujimoto $M$, Watanabe $R$, Ishitsuka $Y$, Okiyama N: Recent advances in dermatomyositis-specific autoantibodies. Curr Opin Rheumatol 2016, 28:636-644. doi:10.1097/BOR.0000000000000329.

3. Gono T, Kuwana M: Current understanding and recent advances in myositis-specific and -associated autoantibodies detected in patients with dermatomyositis. Expert Rev Clin Immuno/ 2020, 16:79-89. doi:10.1080/1744666X.2019.1699059.

4. Travis WD, Costabel U, Hansell DM, King TE Jr, Lynch DA, Nicholson AG, Ryerson CJ, Ryu JH, Selman M, Wells AU, Behr J, Bouros D, Brown KK, Colby TV, Collard HR, Cordeiro CR, Cottin V, Crestani B, Drent M, Dudden RF, Egan J, Flaherty K, Hogaboam C, Inoue Y, Johkoh T, Kim DS, Kitaichi M, Loyd J, Martinez FJ, Myers J, et al.: An official American Thoracic Society/European Respiratory Society statement: Update of the international multidisciplinary classification of the idiopathic interstitial pneumonias. Am J Respir Crit Care Med 2013, 188:733-748. doi:10.1164/rccm.201308-1483ST.

5. Kambouchner M, Levy P, Nicholson AG, Schubel K, Magois E, Feuillet S, Valeyre D, Bernaudin JF, Nunes $\mathrm{H}$ : Prognostic relevance of histological variants in nonspecific interstitial pneumonia. Histopathology 2014, 65:549-560. doi:10.1111/his.12415.

6. Tansey D, Wells AU, Colby TV, Ip S, Nikolakoupolou A, du Bois RM, Hansell DM, Nicholson AG: Variations in histological patterns of interstitial pneumonia between connective tissue disorders and 
their relationship to prognosis. Histopathology 2004, 44:585-596. doi:10.1111/j.13652559.2004.01896.x.

7. Li XR, Peng SC, Wei LQ: Nonspecific interstitial pneumonia overlaps organizing pneumonia in lungdominant connective tissue disease. Int J Clin Exp Pathol 2015, 8:11230-11235 .

8. Debray MP, Borie R, Revel MP, Naccache JM, Khalil A, Toper C, Israel-Biet D, Estellat C, Brillet PY: Interstitial lung disease in anti-synthetase syndrome: initial and follow-up CT findings. Eur $\mathrm{J}$ Radiol 2015, 84:516-523. doi:10.1016/j.ejrad.2014.11.026.

9. Zamora AC, Hoskote SS, Abascal-Bolado B, White D, Cox CW, Ryu JH, Moua T: Clinical features and outcomes of interstitial lung disease in anti-Jo-1 positive antisynthetase syndrome. Respir Med 2016, 118:39-45. doi:10.1016/j.rmed.2016.07.009.

10. Chen A, Karwoski RA, Gierada DS, Bartholmai BJ, Koo CW: Quantitative CT Analysis of Diffuse Lung Disease. Radiographics 2020, 40:28-43. doi:10.1148/rg.2020190099.

11. Bradley B, Branley HM, Egan JJ, Greaves MS, Hansell DM, Harrison NK, Hirani N, Hubbard R, Lake F, Millar AB, Wallace WA, Wells AU, Whyte MK, Wilsher ML, British Thoracic Society Interstitial Lung Disease Guideline Group, British Thoracic Society Standards of Care Committee, Thoracic Society of Australia, New Zealand Thoracic Society, Irish Thoracic Society: Interstitial lung disease guideline: the British Thoracic Society in collaboration with the Thoracic Society of Australia and New Zealand and the Irish Thoracic Society. Thorax 2008, 63 Suppl 5:v1-58. doi:10.1136/thx.2008.101691.

12. Connors GR, Christopher-Stine L, Oddis CV, Danoff SK: Interstitial lung disease associated with the idiopathic inflammatory myopathies: what progress has been made in the past 35 years. Chest 2010, 138:1464-1474. doi:10.1378/chest.10-0180.

13. Witt LJ, Curran JJ, Strek ME: The Diagnosis and Treatment of Antisynthetase Syndrome. Clin Pulm Med 2016, 23:218-226. doi:10.1097/CPM.0000000000000171.

14. Fischer A, Swigris JJ, du Bois RM, Lynch DA, Downey GP, Cosgrove GP, Frankel SK, Fernandez-Perez ER, Gillis JZ, Brown KK: Anti-synthetase syndrome in ANA and anti-Jo-1 negative patients presenting with idiopathic interstitial pneumonia. Respir Med 2009, 103:1719-1724. doi:10.1016/j.rmed.2009.05.001.

15. Enomoto N, Sumikawa H, Sugiura H, Kitani M, Tanaka T, Hozumi H, Fujisawa T, Suda T: Clinical, radiological, and pathological evaluation of "NSIP with OP overlap" pattern compared with NSIP in patients with idiopathic interstitial pneumonias. Respir Med 2020, 174:106201. doi:10.1016/j.rmed.2020.106201.

16. Pesenti A, Musch G, Lichtenstein D, Mojoli F, Amato M, Cinnella G, Gattinoni L, Quintel M: Imaging in acute respiratory distress syndrome. Intensive Care Med 2016, 42:686-698. doi:10.1007/s00134-0164328-1.

17. Liu Y, Luo XJ, Li GQ, Wei LQ, Yu X, Li YM: Increased 90-Day Mortality in Spontaneously Breathing Patients With Paraquat Poisoning: In Addition to Disease Severity, Lung Strain May Play a Role. Crit Care Med 2019, 47:219-228. doi:10.1097/CCM.0000000000003518. 
18. Terragni PP, Rosboch G, Tealdi A, Corno E, Menaldo E, Davini O, Gandini G, Herrmann P, Mascia L, Quintel M, Slutsky AS, Gattinoni L, Ranieri VM: Tidal hyperinflation during low tidal volume ventilation in acute respiratory distress syndrome. Am J Respir Crit Care Med 2007, 175:160-166. doi:10.1164/rccm.200607-9150C.

19. American Thoracic Society. Idiopathic pulmonary fibrosis: diagnosis and treatment. International consensus statement. American Thoracic Society (ATS), and the European Respiratory Society (ERS). Am J Respir Crit Care Med 2000, 161:646-664. doi:10.1164/ajrccm.161.2.ats3-00.

20. Antin-Ozerkis D, Hinchcliff M: Connective Tissue Disease-Associated Interstitial Lung Disease: Evaluation and Management. Clin Chest Med 2019, 40:617-636. doi:10.1016/j.ccm.2019.05.008.

21. Gasparotto $M$, Gatto $M$, Saccon F, Ghirardello A, laccarino L, Doria A: Pulmonary involvement in antisynthetase syndrome. Curr Opin Rheumato/ 2019, 31:603-610.

doi:10.1097/BOR.0000000000000663.

22. Lynch DA, Godwin JD, Safrin S, Starko KM, Hormel P, Brown KK, Raghu G, King TE Jr, Bradford WZ, Schwartz DA, Richard Webb W, Idiopathic Pulmonary Fibrosis Study Group: High-resolution computed tomography in idiopathic pulmonary fibrosis: diagnosis and prognosis. Am J Respir Crit Care Med 2005, 172:488-493. doi:10.1164/rccm.200412-17560C.

23. Occhipinti M, Bosello S, Sisti LG, Cicchetti G, de Waure C, Pirronti T, Ferraccioli G, Gremese E, Larici AR: Quantitative and semi-quantitative computed tomography analysis of interstitial lung disease associated with systemic sclerosis: A longitudinal evaluation of pulmonary parenchyma and vessels. PLoS One 2019, 14:e0213444. doi:10.1371/journal.pone.0213444.

24. Shin KE, Chung MJ, Jung MP, Choe BK, Lee KS: Quantitative computed tomographic indexes in diffuse interstitial lung disease: correlation with physiologic tests and computed tomography visual scores. J Comput Assist Tomogr 2011, 35:266-271. doi:10.1097/RCT.0b013e31820ccf18.

25. Umakoshi H, Iwano S, Inoue T, Li Y, Naganawa S: Quantitative evaluation of interstitial pneumonia using 3D-curved high-resolution CT imaging parallel to the chest wall: A pilot study. PLoS One 2017, 12:e0185532. doi:10.1371/journal.pone.0185532.

26. Huo Z, Li J, Li S, Zhang H, Jin Z, Pang J, Liu H, Shi J, Feng R: Organizing pneumonia components in non-specific interstitial pneumonia (NSIP): a clinicopathological study of 33 NSIP cases. Histopathology 2016, 68:347-355. doi:10.1111/his.12761.

\section{Figures}



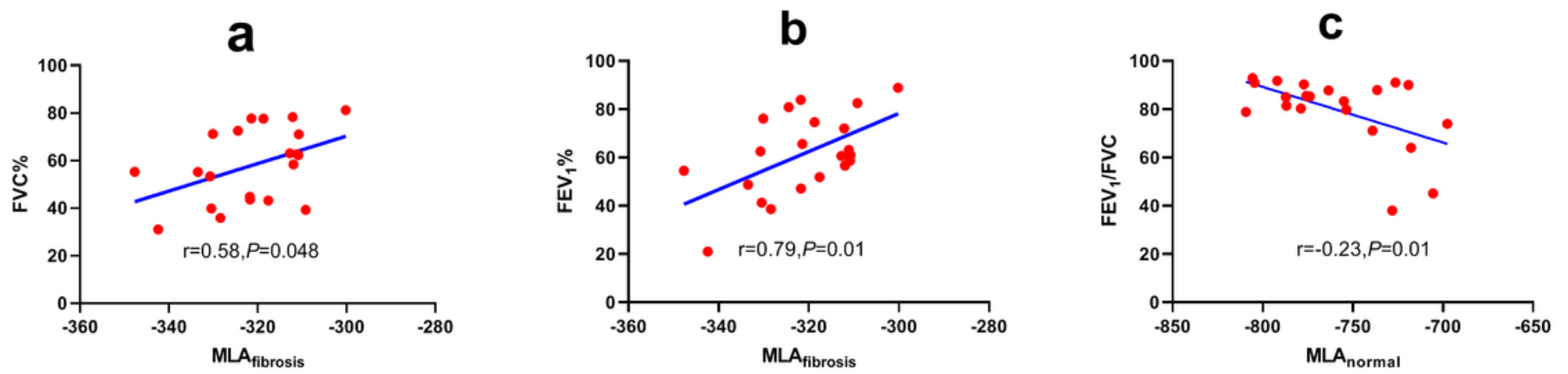

\section{Figure 1}

linear correlation between pulmonary function parameters and aerated lung compartments quantitative values MLA, mean lung attenuation. MLA fibrosis and MLA normal of the extracted whole lung volume with attenuation values of fibrosis, normally lung aerated and hyper inflated area. a,FVC\% and MLA fibrosis(r=0.437,P=0.048 . b,FEV1\% and MLAfibrosis, $r=0.79, P=0.001$. c, FEV1/FVC to and MLAnormal $(r=0.23, P=0.01$. 
a

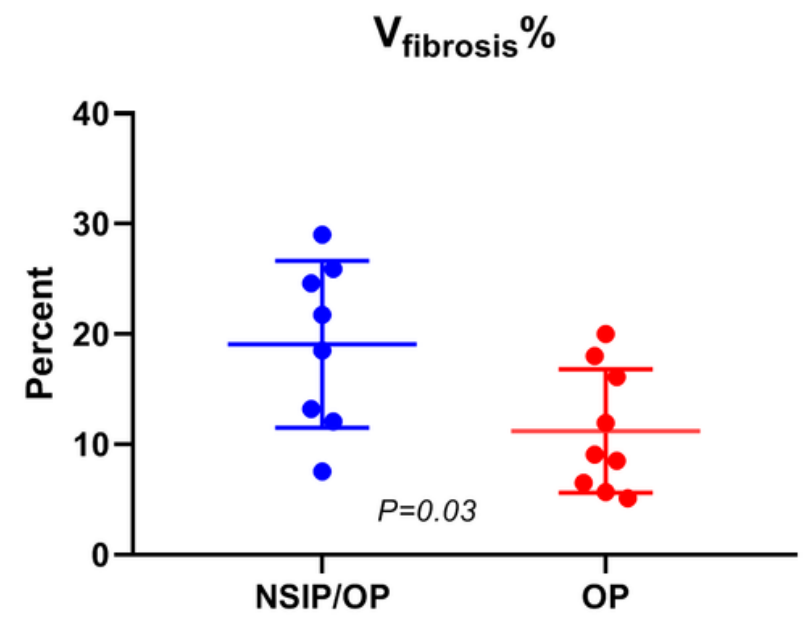

C

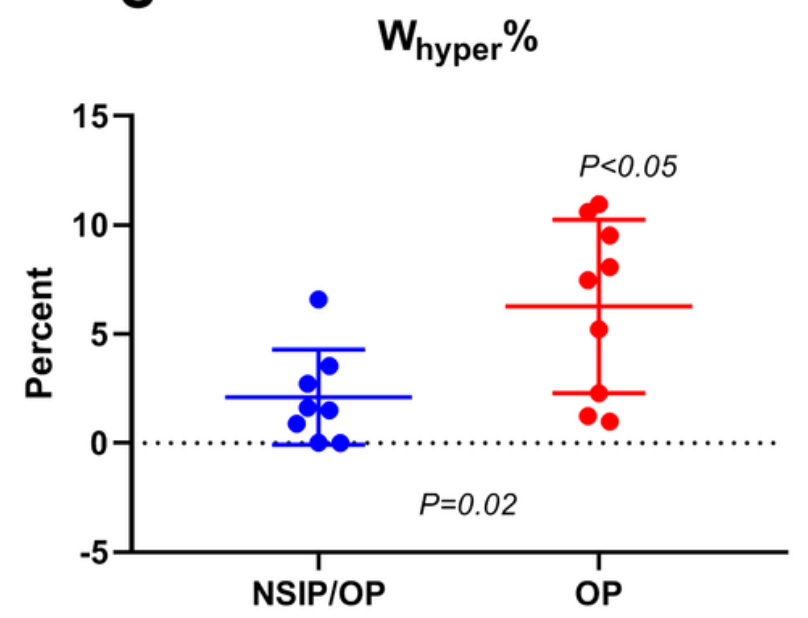

b
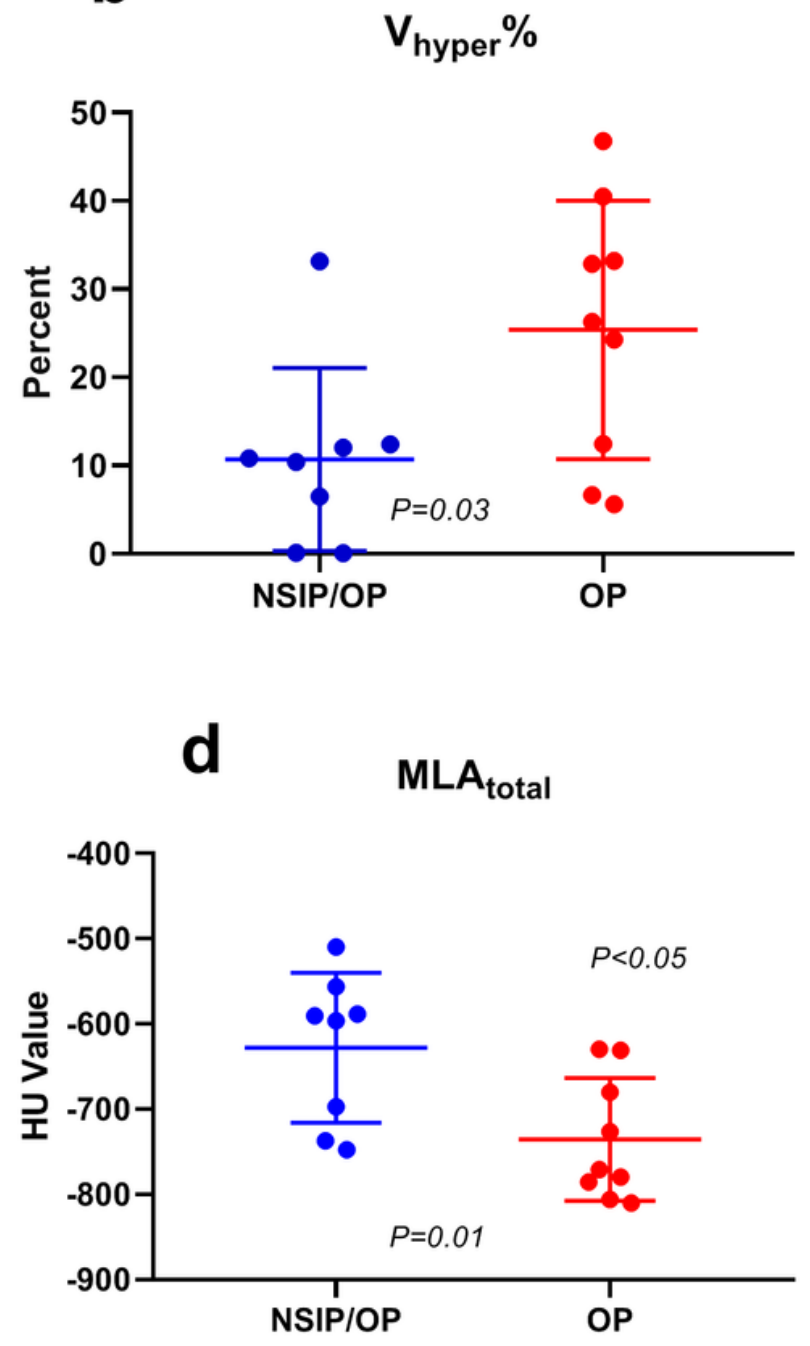

\section{Figure 2}

V fibrosis\%,Vhyper\%, Whyper\% and MLAtotal between patients with NSIP/OP and OP pattern Vfibrosis\%, and Vhyper\%,Volume percentages of the extracted whole lung volume with attenuation values of poorly aerated and fibrosis and hyper inflated area. W hyper \%, Weight percentages of the extracted whole lung volume with attenuation values of hyper inflated area. MLA, mean lung attenuation. MLAtotal, MLA of the extracted whole lung volume with attenuation values of outlined total lung area. $a, V$ fibrosis\%, $P=0.03 . b$, Vhyper\%, $P=0.03 . c$, Whyper\%, $P=0.02$.d,MLAtotal, $P=0.01$. 

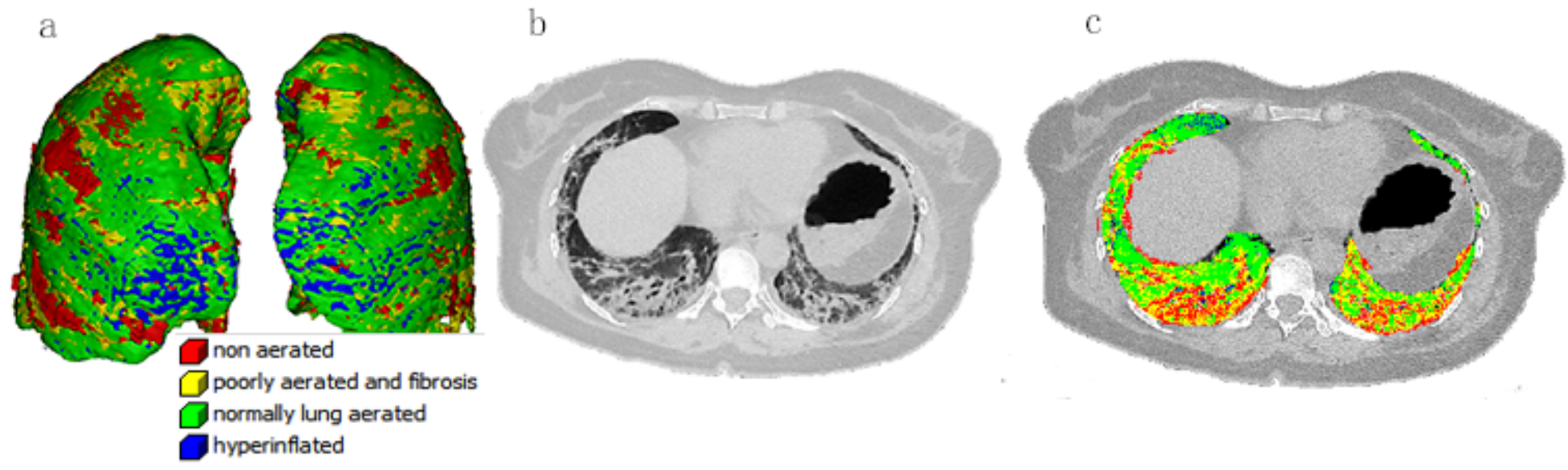

\section{Figure 3}

HRCT patterns and associated 3D model of one female patient with serum anti-PL-12(+) a,All voxels between -1000 and 100 Hu shows the volume of interstitial pneumonia, red area represent non aerated,100 to $+100 \mathrm{HU}$; Yellow area is poorly aerated and fibrosis , -101 to $-500 \mathrm{Hu}$; Green area is normally lung aerated, -501 to $-900 \mathrm{Hu}$; Blue area is hyper inflated ,-901 to-1,000 HU.b,HRCT sign in the lower lung. c,Quantitative axial picture in line with B 